\title{
1 Orthogonal translation initiation using the non-canonical initiator tRNA(AAC) 2 alters protein sequence and stability in vivo
}

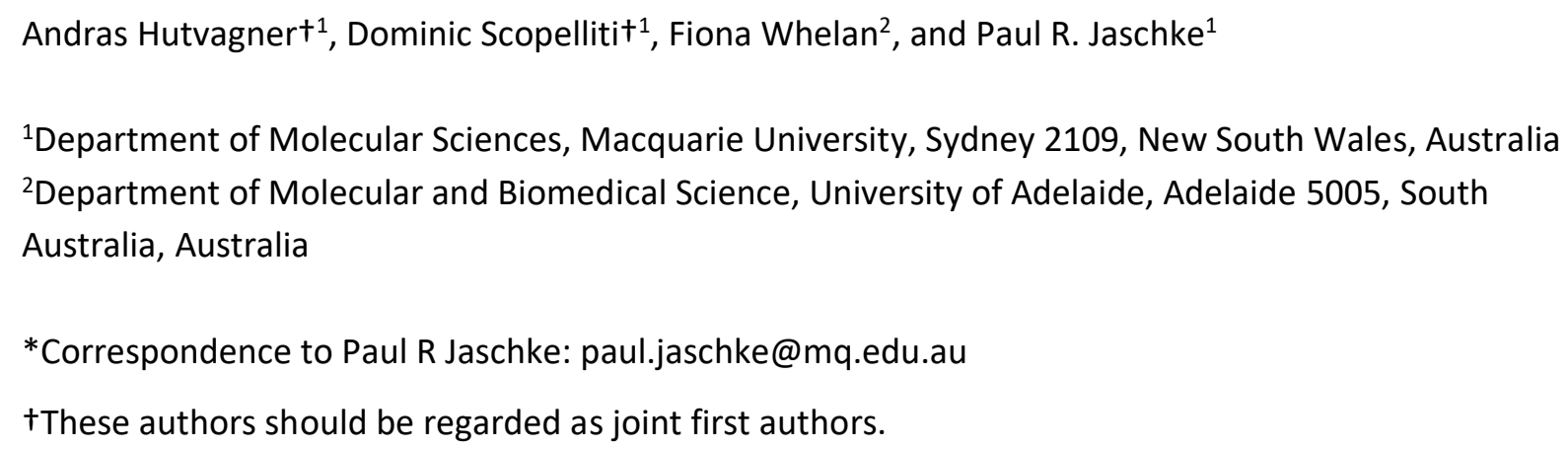

\section{Abstract}

Biological engineers seek to have better control and a more complete understanding of the process of translation initiation within cells so that they may produce proteins more efficiently, as well as to create orthogonal translation systems. Previously, initiator tRNA variants have been created that initiate translation from non-AUG start codons, but their orthogonality has never been measured and the detailed characteristics of proteins produced from them have not been well defined. In this study we created an initiator tRNA mutant with anticodon altered to AAC to be complementary to GUU start codons. We deploy this i-tRNA(AAC) into E. coli cells and measure translation initiation efficiency against all possible start codons. Using parallel reaction monitoring targeted mass spectrometry we identify the $\mathrm{N}$-terminal amino acids of i-tRNA(AAC)-initiated reporter proteins and show these proteins have altered stability within cells. We also use structural modeling of the peptide deformylase enzyme interaction with position 1 valine peptides to interrogate a potential mechanism for accumulation of formylated-valine proteins observed by mass spectrometry. Our results demonstrate that mutant initiator tRNAs have potential to initiate translation more orthogonally than the native initiator tRNA but their interactions with cellular formyltransferases and peptide deformylases can be inefficient because of the amino acid they are charged with. Additionally, engineered initiator tRNAs may enable tuning of in vivo protein stability through initiation with non-methionine amino acids that alter their interaction with cellular proteases. 


\section{Introduction}

Translation initiation is an important step in expressing a functional protein and is the first crucial checkpoint in the translation process [1]. Advances in the understanding of structure and function of translational machinery, and how these biomolecules interact during the initiation process has led to an increased interest in reengineering translation initiation in order to achieve several goals within synthetic biology [2, 3]. Such goals include: enhancing the predictability and control of exogenous DNA expression, engineering biocontainment measures into genetically engineered strains, and the incorporation of non-canonical amino acids at the $\mathrm{N}$-terminus of proteins $[2,4-7]$. Developing orthogonal translation initiation systems may be a suitable way to achieve these goals. An ideal orthogonal translation system would maintain the most important aspects of native translation, ensuring proper functionality, but differ sufficiently from the native system to not interfere with any native expression circuits [2]. Several different orthogonal translation systems have been developed in prokaryotes, many of which focus on translation initiation as a point of engineering $[3,8-16]$.

A critical element of translation initiation is the interaction between the anticodon sequence of the initiator transfer RNA (i-tRNA) and the start codon, usually AUG, at the beginning of a coding sequence on an mRNA transcript. This interaction occurs within the P-site of the ribosome and is

50 facilitated by initiation factors $1-3$ and sequence motifs found on the mRNA (Shine-Dalgarno sequence and start codon), ribosome (regions in the $16 \mathrm{~S}$ rRNA), and the i-tRNA (C-G motif in the anticodon stem, and the C1-A72 mismatch at the acceptor stem) [17-21]. In bacteria, the i-tRNA also carries a formylated methionine, which is incorporated exclusively at the $\mathrm{N}$-terminus of the growing polypeptide chain [22]. Methionine residues lacking formylation are also incorporated throughout the growing polypeptide chain, however these amino acids, along with any other amino acids found internally within a protein are delivered to the growing peptide chain by elongator tRNAs [22]. 

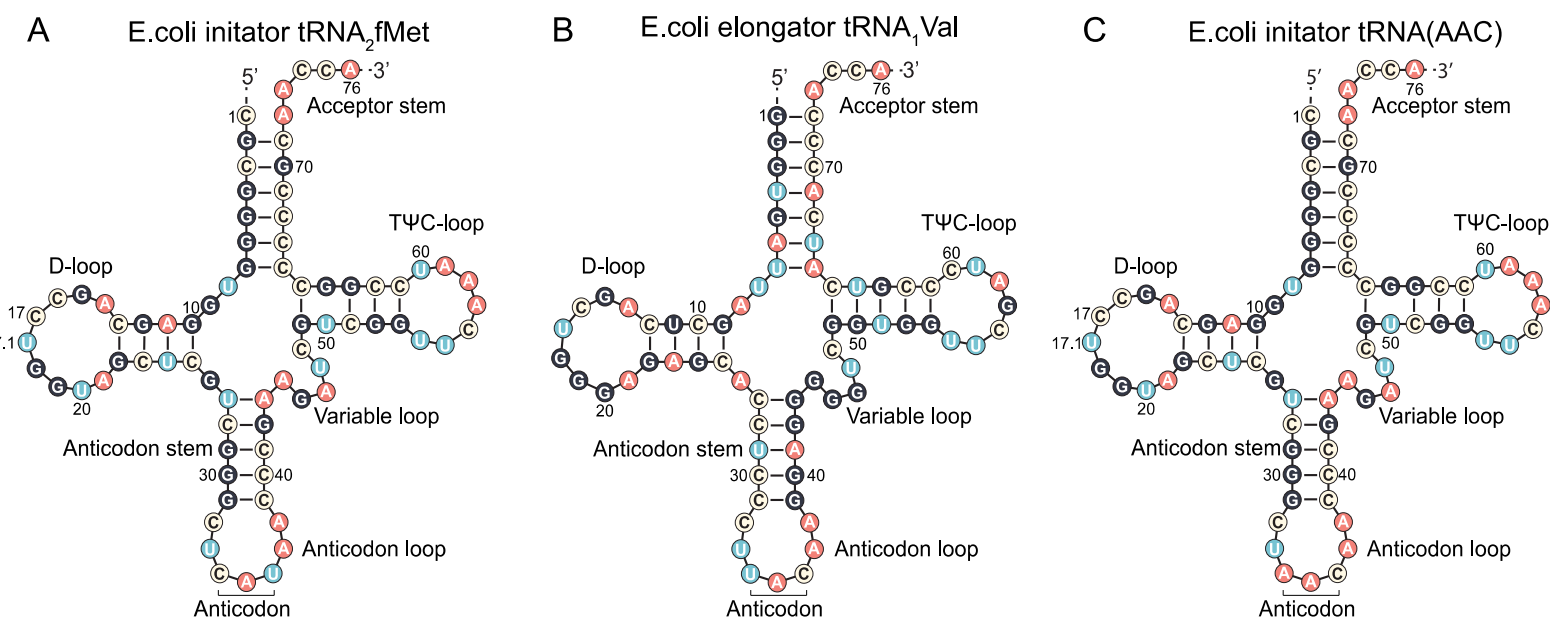

Figure 1. Similarities and differences between E. coli initiator and elongator tRNAs. Escherichia coli initiator tRNA ${ }_{2}{ }^{\mathrm{fMet}}$ (left), the $E$. coli elongator tRNA ${ }_{1}{ }^{\mathrm{Val}}$ (middle) depicted, and the mutant $E$. coli initiator tRNA(AAC) (right).

Although i-tRNAs and elongator tRNAs share an abundance of structural similarities, several sequence motifs unique to the i-tRNA enable this molecule to perform a unique role in translation initiation. Firstly, i-tRNAs possess a mismatch between nucleotides $\mathrm{C} 1$ and $\mathrm{A} 72$ which is a recognition element for methionyl-tRNA transformylase (FMT) [27]. After methionine is charged to i-tRNA in bacteria, the FMT enzyme formylates the bound methionine $[27,28]$. This $f M e t$ residue is essential for subsequent interaction between $\mathrm{i}$-tRNA ${ }^{\mathrm{fMet}}$ and initiation factor 2 prior to recruitment to the $\mathrm{P}$ site of the 305 complex, and some evidence suggests initiation cannot occur without a formylated amino acid bound to i-tRNA [29]. Secondly, a highly conserved 3G-C motif in the anticodon stem 
plays a vital role in P-site binding through interactions with the $16 \mathrm{~S}$ rRNA of the ribosome and initiation factor $3[21,30]$. these initiators might be to other potential start codons. the canonical CAU anticodon. We measured the efficiency of translation initiation of this itRNA(AAC) against all the 63 possible non-AUG start codons and found it is more orthogonal than the native i-tRNA(CAU). Using targeted mass spectrometry methods we identify valine and formylated-valine at the $\mathrm{N}$-terminus of $\mathrm{i}$-tRNA(AAC) initiated proteins, and measure their stability in vivo. Finally, we computationally model the interaction between peptide deformylase and formylvaline peptides to propose a mechanism explaining potential deficiencies in the removal of the formyl group from i-tRNA(AAC)-initiated proteins.

97

\section{Results}

\section{Measuring translation initiation efficiency of i-tRNA(AAC) against all possible start codons}


of metY from MG1655 strain was changed from CAT to AAC and inserted into pULTRA plasmid to make pULTRA::tac-metY(AAC) (Fig. 2A). A control version of this plasmid (pULTRA::tac-Empty)
A

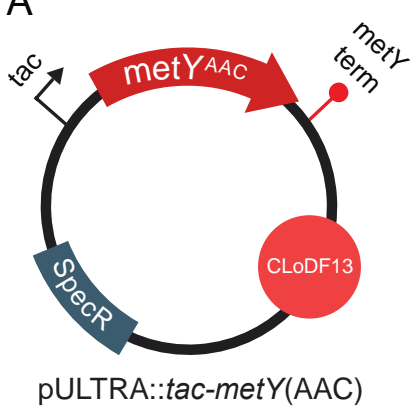

C

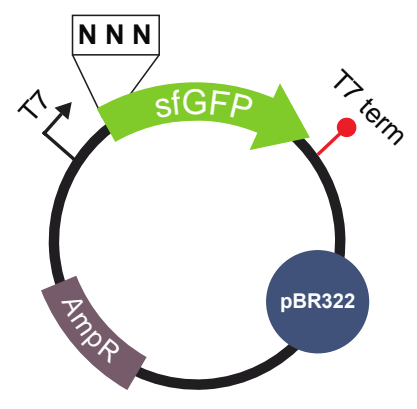

pET20b::T7-(NNN)sfGFP
B

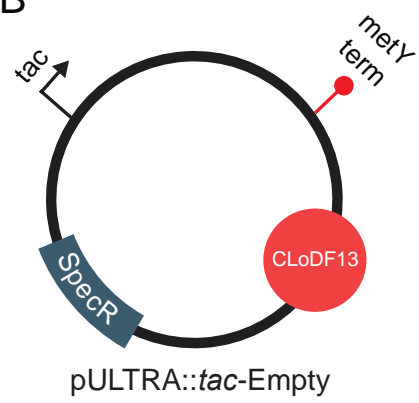

D

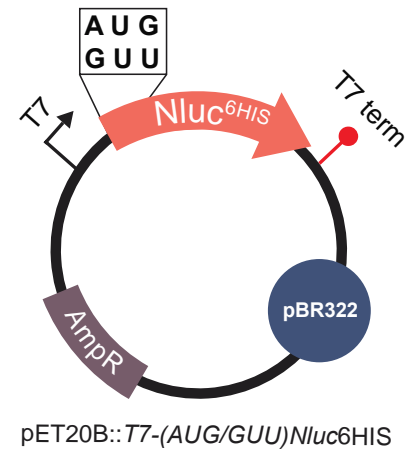

Figure 2. Plasmids used in this study. (A) pULTRA::tac-metY(AAC) expresses the i-tRNA(AAC) anticodon mutant and contains a medium copy ClodF13 origin of replication, spectinomycin resistance gene, inducible tac promoter, and met $Y$ terminator. (B) pULTRA::tac-Empty control plasmid is identical to pULTRA::tac-metY(AAC) but lacks metY gene. (C) pET20b:T7-(NNN)sfGFP expresses the sfGFP reporter with altered start codons and contains a high copy pBR322 origin of replication, ampicillin resistance gene, T7 promoter, and T7 terminator. (D) pET20b:T7(AUG/GUU)Nluc6His expresses the luciferase Nluc with altered start codons, C-terminal 6xHis tag and contains a high copy pBR322 origin of replication, ampicillin resistance gene, $\mathrm{T7}$ promoter, and T7 terminator. All plasmids were designed to have compatible origins of replication and selectable markers.

In order to measure the translation initiation efficiency of mutant i-tRNA(AAC), we used a previously described superfolder GFP (sfGFP) fluorescent reporter library to determine how efficiently i-tRNA(AAC) initiates translation from all 64 start codons [31]. We transformed E. coli strain BL21(DE3)pLysS with: (1) the mutant i-tRNA plasmid harboring the modified tRNA metY gene with an AAC anticodon region (pULTRA::tac-metY(AAC) (Fig. 2A) or pULTRA::tac-Empty (Fig. 2B), and 
126 (2) a set of reporter plasmids harboring sfGFP with all possible start codons (pET20b::T7-

127 (NNN)sfGFP) (Fig. 2C).

128 To investigate how the presence of $\mathrm{i}$-tRNA(AAC) within the $E$. coli cell affects the translation

129 efficiency of (NNN)sfGFP, we analyzed the bulk cell and population fluorescence (Arb.U.) of strains

130 harboring the pULTRA::tac-metY(AAC) and pET20b::T7-(NNN)sfGFP plasmids, under inducing

131 conditions and compared to cells containing pULTRA::tac-Empty. Relative fluorescence of cells

132 containing the pET20b::T7-(NNN)sfGFP reporters and the control plasmid pULTRA::tac-Empty were

133 broadly similar to those reported in Hecht, Glasgow [31], with the strongest initiation events

134 occurring from canonical start codons AUG, GUG, and UUG (Fig. 3). In contrast, when cells contained

135 pULTRA::tac-metY(AAC), we observed an increase in translation initiation from GUU start codon of

136 8-fold over that seen in cells containing pULTRA::tac-Empty (Fig. 3). Similarly, measurements of the

137 same cultures using flow cytometry showed unimodal cell populations for all start codons and a 10-

138 fold increase in fluorescence from GUU start codon (Fig. S1).

139 To determine if there were any other significantly differentially initiating start codons as a

140 result of $\mathrm{i}$-tRNA(AAC), we repurposed the differential expression analysis for sequence count data 2

141 (DESeq2) method normally used for transcriptomics [34]. Considering that the fluorescence data

142 gathered in this study was in the form of integer count data and the number of replicates allowed

143 the statistical models to hold true, we reasoned that DESeq2 was appropriate for this analysis. By

144 designating the set of strains containing the pULTRA::tac-Empty and pULTRA::tac-metY(AAC)

145 plasmids as sample conditions, we analyzed the efficiency of i-tRNA(AAC) initiation against all 64

146 possible start codons. DESeq2 analysis of the bulk fluorescence and flow cytometry data showed

147 only start codon GUU was significantly ( $p$-value $<0.01)$ differentially expressed in the presence of i-

148 tRNA(AAC) (Fig. 4). This result shows that the translation initiation enhancing effect of $i$-tRNA(AAC) is

149 limited to its cognate start codon GUU. 
bioRxiv preprint doi: https://doi.org/10.1101/2021.05.25.445580; this version posted May 25, 2021. The copyright holder for this preprint (which was not certified by peer review) is the author/funder, who has granted bioRxiv a license to display the preprint in perpetuity. It is made available under aCC-BY-ND 4.0 International license.

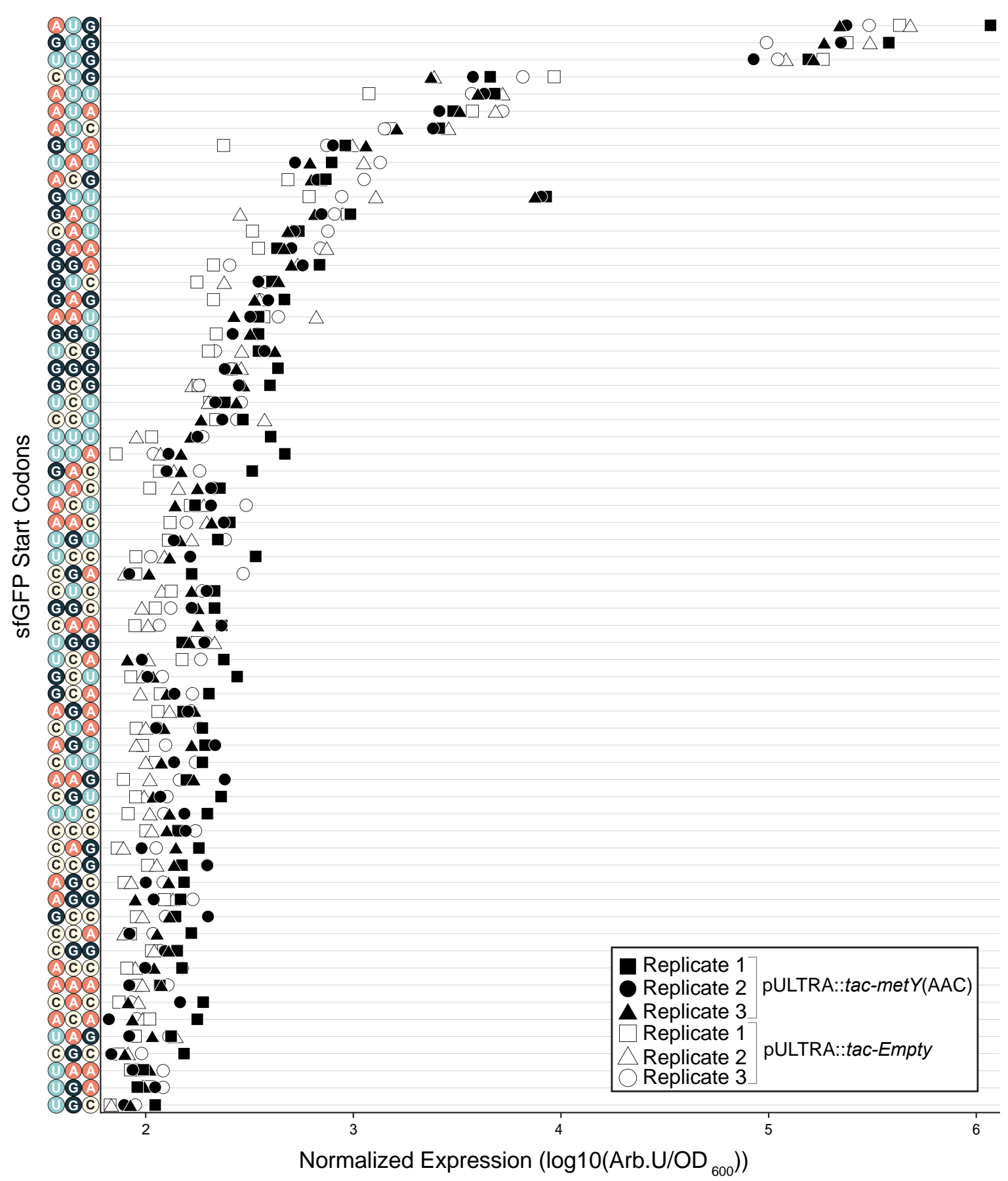

151 Figure 3. Efficiency of translation initiation of all sfGFP variants using the mutant i-tRNA(AAC).

152 Normalized bulk cell fluorescence (Arb. U./OD 600 ) of all sfGFP start codon variants was captured from 153 cells grown to mid-log phase $\left(0.6 \mathrm{OD}_{600}\right)$ in the presence of the i-tRNA(AAC) induced with $1 \mathrm{mM}$ IPTG 154 for 1-hour prior to measurement. 


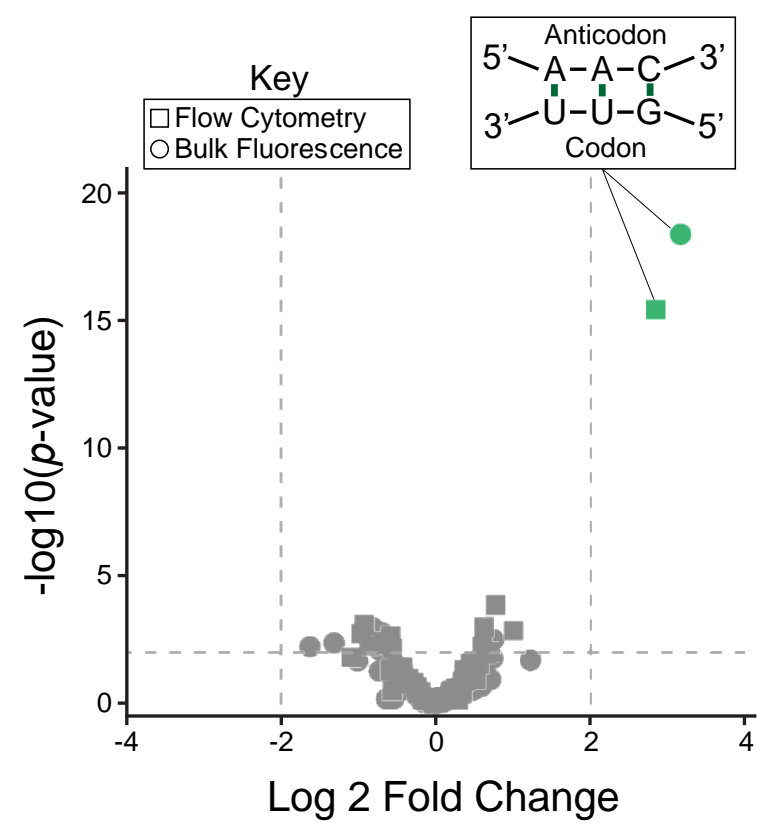

157 Figure 4. DESeq2 analysis of translation initiation from i-tRNA(AAC) shows only translation 158 initiation from cognate GUU start codon increased by mutant i-tRNA(AAC). DEseq2 analysis was 159 used to compare the normalized bulk cell fluorescence and flow cytometry fluorescence (Arb. $\left.160 U . / \mathrm{OD}_{600}\right)$ of cells containing i-tRNA(AAC) and sfGFP reporter library, to control cells containing 161 pULTRA:tac-Empty and sfGFP reporter library. determine whether it had any effects on cellular fitness. We cultured BL21(DE3)::pLysS cells carrying either pULTRA::tac-metY(AAC) or pULTRA::tac-Empty plasmids under either inducing or non-

166 inducing conditions, and measured both growth rate and final $\mathrm{OD}_{600}$ for both. The results of this

167 analysis showed that there was a significant decrease in the growth rate of $i$-tRNA(AAC) expressing

168 cells $(p<0.05)$, while no significant changes to maximum cell density were seen (Fig. 5). The uninduced condition showed no significant changes to maximum cell density or growth rate. 


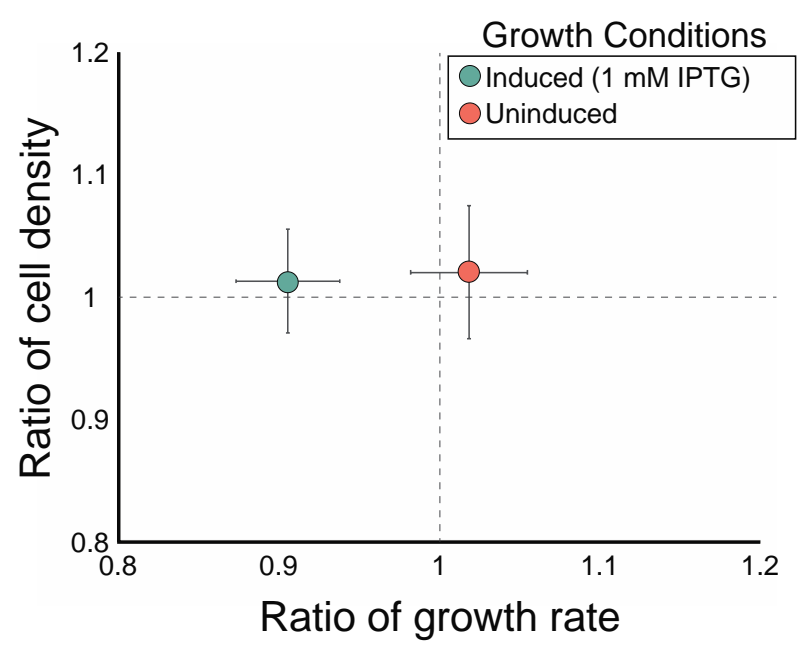

170 Figure 5. Fitness analysis of a strain harboring pULTRA::tac-metY(AAC). Ratios of growth rate and maximum cell density were determined for strains harboring pULTRA::tac-metY(AAC) and compared to pULTRA::tac-Empty control. All strains were grown in LB in the presence of spectinomycin and chloramphenicol in biological triplicate. $1 \mathrm{mM}$ IPTG was added to the induced condition, whereas equivalent amounts of sterile water was added to the uninduced condition. Error bars represent one standard deviation.

\section{Identification of the amino acid incorporated onto the $\mathrm{N}$-terminus of proteins expressed} to confirm which amino acid was aminoacylated to $\mathrm{i}$-tRNA(AAC). To identify the $\mathrm{N}$-terminal amino acid used to initiate translation from GUU start codons, we created two new C-terminally His-tagged NanoLuc luciferase (Nluc) reporter plasmids containing GUU and AUG start codons: pET20b:T7(GUU)Nluc6HIS and pET20b:T7-(AUG)Nluc6HIS (Fig. 2D). To express the (GUU)Nluc protein while also expressing i-tRNA(AAC), along with appropriate controls, we grew BL21(DE3)pLysS containing pET20b:T7-(GUU)Nluc6HIS or pET20b:T7-(AUG)Nluc6HIS along with either pULTRA::tac-metY(AAC) or pULTRA::tac-Empty. Next, we Ni-NTA purified the Nluc proteins, digested with trypsin, and subjected the resulting peptides to mass spectrometry. The mass spectrometry approach parallel reaction monitoring (PRM) was used to identify

189 the amino acid incorporated onto the $\mathrm{N}$-terminus of the Nluc reporters. The main benefit of using 190 PRM is that this method allows us to predefine specific targets, providing a high degree of selectivity and sensitivity by excluding undesirable signals. The isolation list used to specify the targeted 
bioRxiv preprint doi: https://doi.org/10.1101/2021.05.25.445580; this version posted May 25,2021 . The copyright holder for this preprint

(which was not certified by peer review) is the author/funder, who has granted bioRxiv a license to display the preprint in perpetuity. It is made available under aCC-BY-ND 4.0 International license.

192 peptides in this PRM analysis included several internal Nluc peptides and the 20 possible amino acids

193 with and without formylation at the N-terminus (File S1). As expected, in cells carrying pET20b:T7-

194 (AUG)Nluc6HIS and pULTRA::tac-Empty plasmids, we found that N-terminal peptides of Nluc

195 proteins carried methionine exclusively $(807.8854 \mathrm{~m} / \mathrm{z}$ ) (Fig. 6A). Similarly, in cells carrying

196 pET20b:T7-(GUU)Nluc6HIS and pULTRA::tac-Empty plasmids, all N-terminal peptides had only

197 methionine (Fig. 6B), supporting previous results on initiation from non-canonical start codons [31].

198 In contrast, cells carrying both pET20b:T7-(GUU)NIuc6HIS and pULTRA::tac-metY(AAC)

199 plasmids showed two different precursor ions $(791.8997 \mathrm{~m} / \mathrm{z}$ and $805.8976 \mathrm{~m} / \mathrm{z})$ that were absent in

200 the (AUG)Nluc samples (Fig. 6C). These two new precursor $m / z$ values are consistent with $\mathrm{N}$-terminal

201 peptides bearing a valine and a formylated valine residue on the $\mathrm{N}$-terminus of the (GUU)Nluc

202 protein and was confirmed by subsequent MS2 analysis (Fig. 6C, insets). Interestingly, in addition to

203 valine bearing $\mathrm{N}$-terminal peptides, methionine (but not formylated-methionine) bearing $\mathrm{N}$-terminal

204 peptides were also identified, suggesting a heterogenous population (Fig. S2). 
bioRxiv preprint doi: https://doi.org/10.1101/2021.05.25.445580; this version posted May 25, 2021. The copyright holder for this preprint (which was not certified by peer review) is the author/funder, who has granted bioRxiv a license to display the preprint in perpetuity. It is made available under aCC-BY-ND 4.0 International license.

A

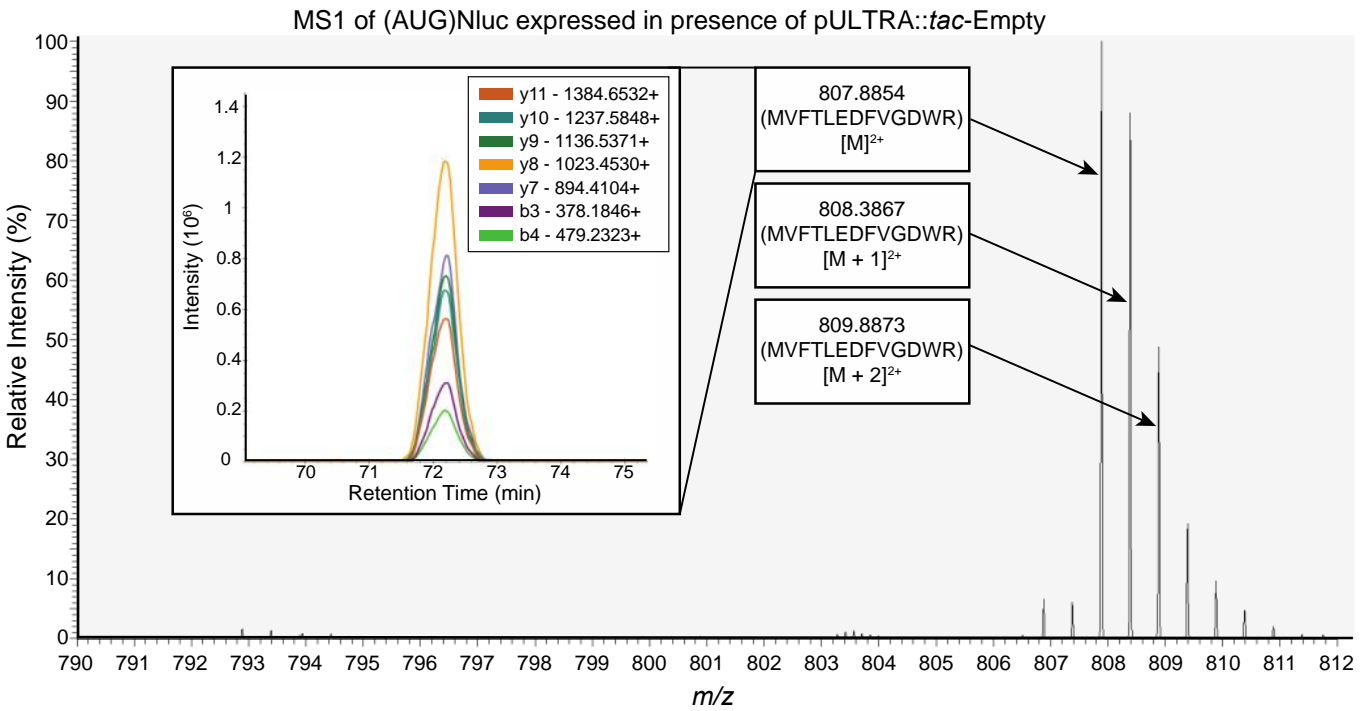

B
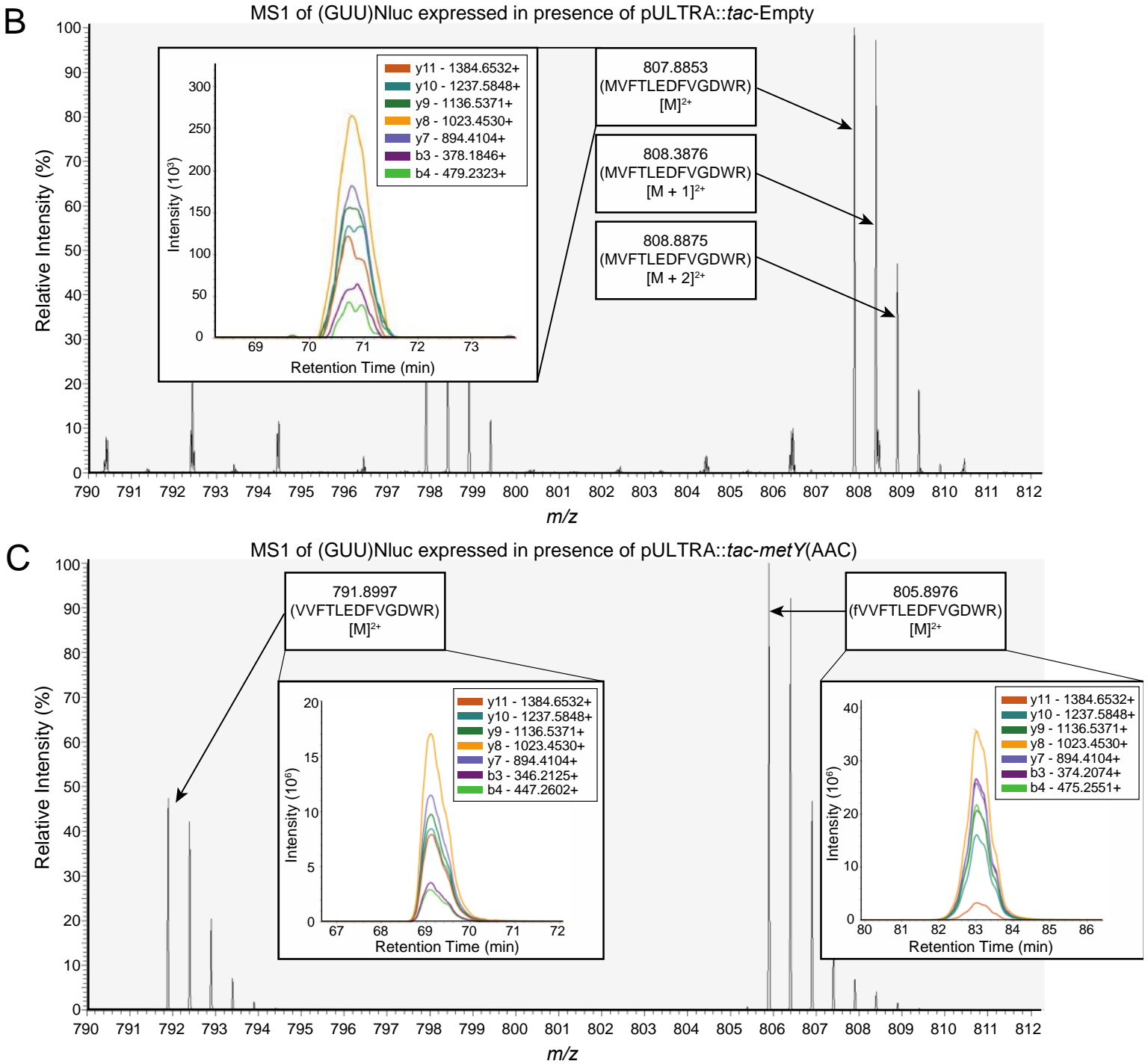

Figure 6. $\mathrm{N}$-terminal amino acid residue identification of Nluc using targeted mass spectrometry. Nluc-6His reporter proteins carrying either AUG or GUU start codons were Ni-NTA purified from three different BL21(DE3)pLysS strains possessing either the pULTRA::tac-metY(AAC) or pULTRA::tacEmpty. (A) MS1 scan during retention time range of 68-73 minutes of Nluc reporter protein expressed in BL21(DE3)pLysS (pULTRA::tac-Empty; pET20b:T7-(AUG)Nluc6HIS). Labelled precursor ion peaks $(807.8854 \mathrm{~m} / \mathrm{z}$ ) consistent with an $\mathrm{N}$-terminal peptide bearing methionine 
212 (MVFTLEDFVGDWR) and their respective isotopes at the N-terminus are shown. Inset shows MS2 $\mathrm{y}$

213 and $b^{-}$series product ion signals used to confirm amino acid sequence of $\mathrm{N}$-terminal peptide. (B)

214 MS1 scan of Nluc during retention time range of 68-73 minutes of Nluc reporter protein expressed in

215 BL21(DE3)pLysS (pULTRA::tac-Empty; pET20b:T7-(GUU)Nluc6HIS). Labelled precursor ion peaks

$216(807.8853 \mathrm{~m} / \mathrm{z})$ consistent with an $\mathrm{N}$-terminal peptide bearing methionine (MVFTLEDFVGDWR) and

217 their respective isotopes at the $\mathrm{N}$-terminus are shown, with no evidence of a peptide with an $\mathrm{N}$ -

218 terminal valine residue present. Inset shows MS2 $\mathrm{y}^{-}$and $\mathrm{b}^{-}$series product ion signals used to confirm

219 amino acid sequence of $\mathrm{N}$-terminal peptide. (C) MS1 scan between retention times 68-84 minutes of

220 Nluc reporter protein expressed in BL21(DE3)pLysS (pULTRA::tac-metY(AAC); pET20b:T7-

221 (GUU)Nluc6HIS). Labelled precursor ion peaks (791.8997 m/z and $805.8976 \mathrm{~m} / \mathrm{z}$ ) are consistent with

$222 \mathrm{~N}$-terminal peptides bearing either valine (VVFTLEDFVGDWR) or formylated valine

223 (fVVFTLEDFVGDWR). Insets show MS2 $\mathrm{y}^{-}$and $\mathrm{b}^{-}$series product ion signals used to confirm amino acid

224 sequence of $\mathrm{N}$-terminal peptide.

226 Determination of the stability of (GUU)Nluc proteins within E. coli

With the knowledge that the majority of the N-terminal residues of (GUU)Nluc were either

valine or formylated valine, we wanted to measure whether there were any effects on the stability

of the reporter protein from this altered $\mathrm{N}$-terminal amino acid. To measure in vivo protein stability

of the Nluc reporters using the enzymatic activity of the protein (luminescence) as a proxy for

231 protein levels, we spun down and washed overnight cultures of BL21(DE3)pLysS strains containing

232 combinations of the reporter and i-tRNA expressing plasmids, pulsed them with IPTG for 1 hour,

233 followed by growth in repressing conditions for 12 hours. Early time points in the luminescence

234 dataset showed considerably less luminescence from reporter proteins expressed from a GUU start

235 codon, as opposed to reporters expressed from the native AUG start codon. These findings are in

236 agreement with the findings of the bulk fluorescence and flow cytometry, which showed that

237 translation initiation of sfGFP from GUU start codons in the presence of the mutant $i-\operatorname{tRNA}(A A C)$ is

238 several orders of magnitude less efficient than translation initiation from AUG codons by native i-

239 tRNA-fMet (Fig. 3). 
A

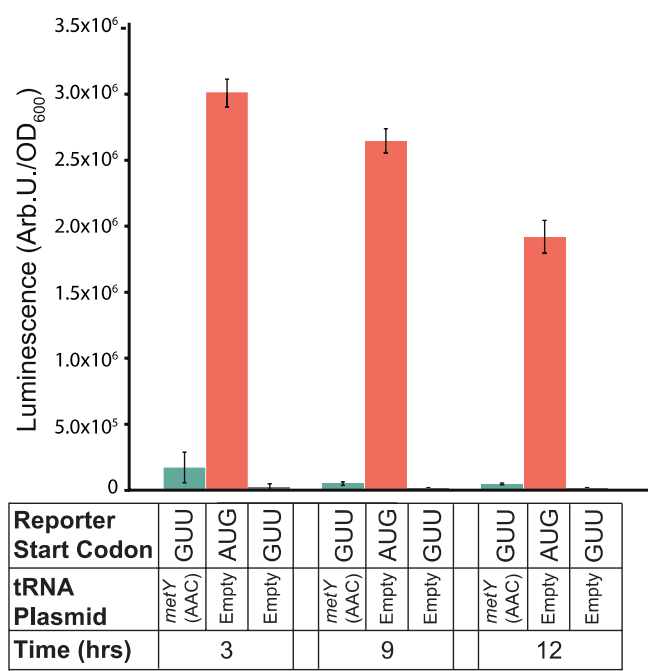

B

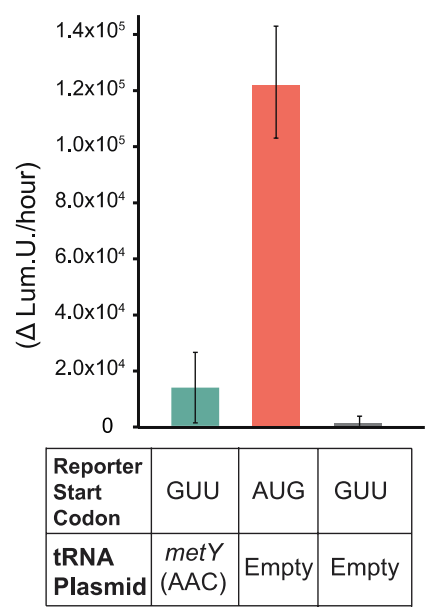

C

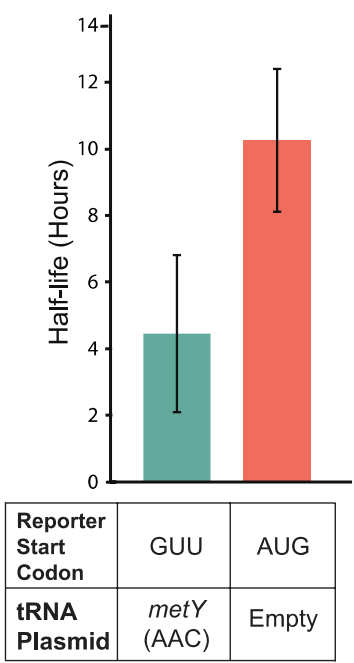

Figure 7. In vivo stability of Nluc proteins expressed in the presence and absence of $i$-tRNA(AAC).

242

243

244

245

246

247

248

249

250

251

252

253

254

255

256

257 Nluc luminescence was analysed from BL21(DE3)pLysS strains grown in biological triplicates. Saturated cultures of each strain were back diluted to $0.1 \mathrm{OD}_{600}$ and grown for 2 hours prior to a 1hour pulse induction with $1 \mathrm{mM} \mathrm{IPTG}$. Cells were then washed and resuspended in repressing conditions (LB, 2\% glucose) and grown for 12 hours, with luminescence measured every 3 hours with the H1 Hybrid Multi-Mode Reader at 100 gain setting. (A) Normalized luminescence from E. coli BL21(DE3)pLysS cells harbouring either pULTRA::tac-metY(AAC)/ pET20b:T7-(GUU)Nluc6HIS (green), pULTRA::tac-Empty/ pET20b:T7-(AUG)Nluc6HIS (orange), or pULTRA::tac-Empty/ pET20b:T7(GUU)Nluc6HIS plasmids (grey) at 3, 9, and 12 hours post induction. (B) Calculated rates of luminescence decrease per hour from 3- and 12-hours luminescence readings post induction. (C) Half-lives of Nluc calculated using normalized luminescence from 3- and 12-hours post induction.

We observed a relatively steady decrease in luminescence over the 12 hour time course for (GUU)Nluc expressed in the presence of i-tRNA(AAC) and the native (AUG)Nluc expressed in the absence of i-tRNA(AAC) (Fig. 7A). We observed very low signal and no change in measurable levels of luminescence from the (GUU)Nluc reporter expressed in the absence of $i$-tRNA(AAC), over the 9 hour time-course (Fig. 7A).

The rate of degradation was found to be approximately 8 times faster in the native (AUG)Nluc samples compared to the (GUU)Nluc samples (Fig. 7B), but the half-life of (GUU)Nluc was only 4.5 hours compared to 10.3 hours for (AUG)Nluc (Fig. 7C) indicating proteins expressed using itRNA(AAC) were significantly less stable than from the (AUG)Nluc control. 


\section{Comparing formyl-valine and formyl-methionine tripeptides as substrates for peptide}

266

267

268

269

270

271

272

273

274

275

276

277

278

280

281

282

283

284

285

286

287

288

\section{deformylase}

Given that we detected a strong signal of formylated valine peptides from (GUU)Nluc expressed in the presence of $\mathrm{i}$-tRNA(AAC) (Fig. 6C), but no formylated methionine signals from (GUU)Nluc (Fig. 6B), and only weak signals in (AUG)Nluc in the absence of i-tRNA(AAC) (Fig. S3), this suggested to us that the interaction between formylated valine and the enzyme responsible for removing the formyl group was altered from that of formyl methionine. We next wanted to understand the reason for this apparent difference. In E. coli the formyl group is normally removed from the $\mathrm{N}$-terminal methionine by the essential enzyme peptide deformylase. Thus, we investigated the relative binding stability of XAM peptides (where $X$ is any residue except proline) to the $E$. coli enzyme peptide deformylase in silico using a molecular mechanics approach. Here, we have studied the $\mathrm{Ni}^{2+}$ bound enzyme structure ( $\mathrm{pdb}$ code: $1 \mathrm{bs} 6$ ) as this is has been shown to be an active deformylase [35] and has been defined bound to partial substrate peptide MAS [36]. Molsoft ICM-Pro software was used to calculate the relative difference in binding free energy $(\Delta \Delta \mathrm{G})$ between mutant and wildtype complexes, computed from the sum of van der Waals attraction and repulsion, electrostatic interactions, change in entropy, hydrogen bond formation and solvent interactions using the Internal Coordinate Force Field (ICFF) [37]. A Monte Carlo simulation of side chain repacking in the vicinity of the mutated residue was performed to optimise the lowest energy mutant conformation and binding interaction while maintaining the geometry of the peptide backbone [38-40].

A negative $\Delta \Delta G$ indicates a higher stability interaction; a positive $\Delta \Delta \mathrm{G}$ indicates a lower stability interaction, while a $\Delta \Delta \mathrm{G}$ of $\geq 2.5 \mathrm{kcal} / \mathrm{mol}$ is considered a significant difference [38]. Thus, peptides with $Q, V, S, N, E, C, W, A, G$ or $D$ at position 1 (pdb code $1 \mathrm{bs} 6$, chain $D$ [36] are predicted from this analysis to have significantly lower stability binding in complex with E. coli peptide deformylase (1bs6, chain A) (Table 1). In support of this model, it has previously been demonstrated that this enzyme cannot hydrolyse a formylated tetrapeptide with Ala at position 1 (fAGSE) [41]. 


\begin{tabular}{|c|c|}
\hline Amino Acid & $\Delta \Delta \mathbf{G}$ \\
\hline D & 6.06 \\
\hline G & 5.75 \\
\hline A & 4.51 \\
\hline W & 4.07 \\
\hline C & 3.73 \\
\hline E & 3.41 \\
\hline N & 3.37 \\
\hline S & 3.21 \\
\hline V & 2.89 \\
\hline Q & 2.75 \\
\hline R & 2.25 \\
\hline H & 2.05 \\
\hline Y & 2.01 \\
\hline T & 1.94 \\
\hline F & 1.92 \\
\hline I & 1.90 \\
\hline L & 1.75 \\
\hline K & 1.31 \\
\hline M & 0.00 \\
\hline
\end{tabular}

292

293

294

295

296

297

$\Delta \Delta \mathrm{G}(\mathrm{kcal} / \mathrm{mol})$ is the difference in Gibbs free energy $(\Delta \mathrm{G})$ of mutant peptide binding relative to wild type peptide, $\Delta \Delta \mathrm{G}=\Delta \mathrm{G}^{\text {mutant }}-\Delta \mathrm{G}^{\mathrm{wt}}$.

A more detailed prediction of possible binding poses was performed by docking models of formylated substrates fMAS, fVAS and fAAS into the Ni-bound active site of peptide deformylase (1bs6, chain A). The docking score (Edoc) represents a composite score where the lower the score, the better the binding, and is calculated from a combination of hydrogen bond grid energy (Egb), electrostatic grid potential (Ege), hydrophobic potential (Egs) and van der Waals interaction (Egv) (Tables S1-S3). The best scoring example of each peptide indicates a binding preference in the order fMAS>fVAS>fAAS (Edoc scores) (Table 2). This correlated with Egv and Egs scores, which demonstrated the highest variance between mutant peptides for the best poses, indicating that van der Waals and hydrophobic interactions are likely the basis of substrate selectivity. Docking was performed in triplicate; and the most negative scoring docked peptides show very limited variance in backbone architecture proximal to the active site (Fig. 8A), with the fMAS peptide having the formyl carbonyl carbon coordinated in proximity to the catalytic nucleophile W1 (3.0 ̊̊), the backbone 
amide hydrogen of L91 (2.3 $)$, and the active site Ni atom (3.4 $\mathrm{A})$ (Fig. 8B), consistent with the

Wu et al. [42]. The highest scoring docked fVAS peptide shows a similar orientation, with the formyl

311 (2.7 ̊̊) (Fig. 8C). Thus, no profound differences in the active site localisation of the formyl group are

312 evident, likely indicating that this binding event would be competent for catalysis. The molecular

313 determinants of specificity are clearer when rendered as a 2-dimensional interaction diagram. A

314 decrease in hydrophobic interactions is evident for fVAS, becoming more pronounced for fAAS

315 relative to fMAS (Fig. 9). The progressive decrease in accessible surface area for the side chain at

316 position 1 may explain the apparent decreased catalytic efficiency in hydrolysis of the formyl group

317 of $\mathrm{fV}$ bearing proteins, evidenced by their detection by PRM, and the absence of formylated

318 methionine in this analysis (Fig. 6).

319 Table 2 ICM-Pro ligand docking scores for peptides fMAS, fVAS and fAAS

\begin{tabular}{|l|r|r|r|r|r|}
\hline Peptide & Edock & Egl & Ege & Egs & Egv \\
\hline fMAS & -32.27 & -5.96 & -12.04 & -1.57 & -61.88 \\
\hline fVAS & -30.47 & -7.18 & -13.46 & -1.45 & -57.49 \\
\hline fAAS & -27.73 & -7.17 & -13.08 & -0.74 & -51.01 \\
\hline
\end{tabular}

A

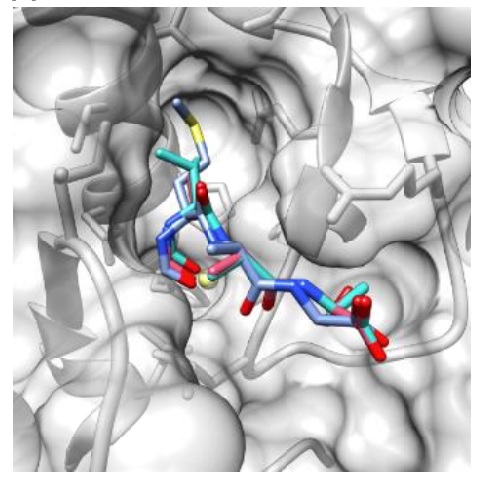

B

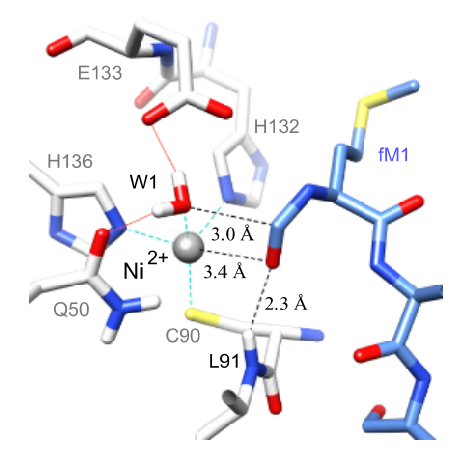

C

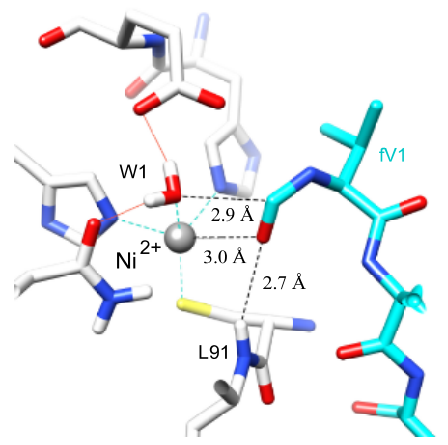

321

322

323

324

325

326

327

328

329

Figure 8. Overlay of models of highest scoring docking pose of formylated peptides fMAS, fVAS and fAAS in the substrate binding pocket of $\mathrm{Ni}^{2+}$ bound $E$. coli peptide deformylase. (A) A model of E. coli peptide deformylase (pdb code: 1 bs6) is shown in grey ribbon, with the surface rendered to illustrate the peptide binding pocket (sidechains, grey sticks; active site $\mathrm{Ni}^{2+}$ is shown as a yellow sphere). The highest scoring docking poses for peptides fMAS (blue), fVAS (cyan) and fAAS (pink) are illustrated as sticks, with atoms coloured by type (sulphur, yellow; oxygen, red; nitrogen, blue). Figures were prepared in Chimera. (B) The active site binding interactions of the highest scoring pose of fMAS and (C) fVAS peptides, illustrating GIn50 and Glu133 hydrogen bonding to water (W1) (red lines); and nickel ( $\mathrm{Ni}^{2+}$, grey sphere) coordination by Cys90, His132 and His136 (cyan dashed lines). 
Distances between modelled formyl carbon and $\mathrm{W} 1, \mathrm{Ni}^{2+}$ and Leu91 backbone amide are illustrated

A

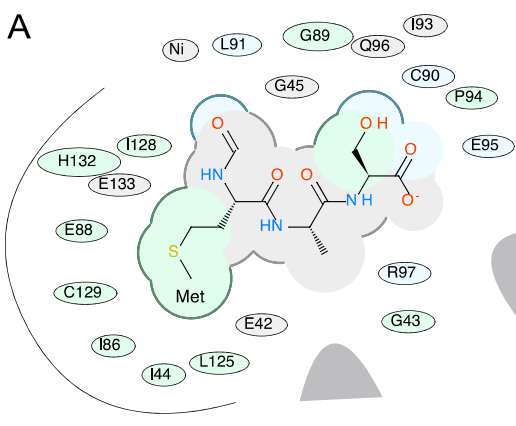

336

337

338

339

340

341

342

343

\section{Discussion}
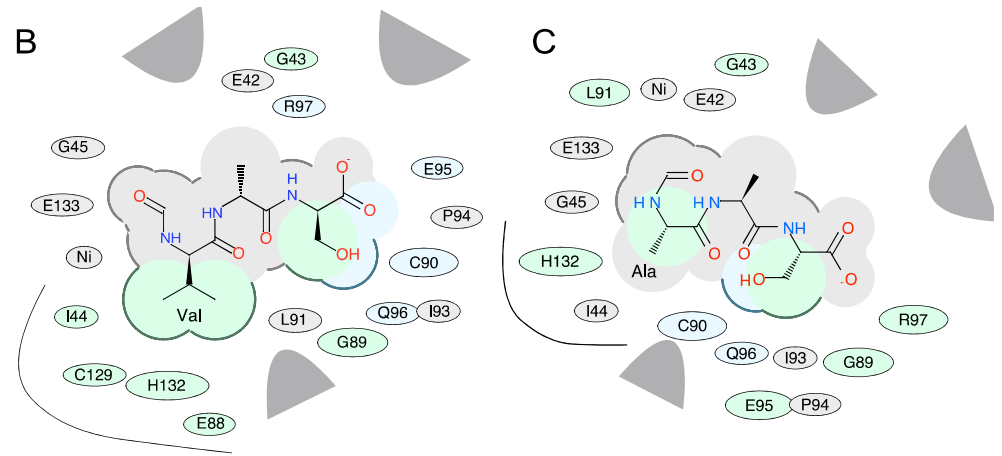

Figure 9. E. coli peptide deformylase binding pocket interactions of in silico docked peptides fMAS, fVAS and fAAS. 2D chemical interaction diagram for best scoring docked fMAS peptide (A), fVAS (B) and fAAS (C). The shading represents hydrophobic interactions (green), hydrogen bond acceptors (blue); van der Waals contacts (grey residues); grey parabolas represent large accessible surface areas; thick lines around ligands illustrate accessible surface; and the size of the residue oval shapes represents the strength of the contact. Black curved lines highlight the side chain interactions for residues at position 1 (Met, $\mathrm{Val}$ and $\mathrm{Ala}, \mathrm{A}-\mathrm{C}$, respectively). Figures prepared in ICM-Pro.

In this study, we directly assessed the orthogonality of translation initiation from a mutant initiator tRNA in E. coli for the first time. To our knowledge, this is the first instance that the DESeq2 software was used to analyse the protein expression differences in the context of translation initiation using mutant i-tRNAs, and non-canonical start codons. Additionally, we identified the amino acids and their formylation status carried by the mutant i-tRNA(AAC). Finally, we modelled the interaction of these formylated amino acids with peptide deformylase to explain the apparent slow kinetics of deformylating valine bearing proteins.

Using high-resolution PRM mass spectrometry we clearly show there is a heterogenous population of both methionine and valine bearing N-terminal peptides on (GUU)Nluc expressed in the presence of $\mathrm{i}$-tRNA(AAC) (Fig. 6). Based on past work showing that the native initiator tRNA can weakly recognize GUU start codons and initiate translation [31, 32], coupled with our detection of methionine bearing Nluc peptides in both the presence (Fig. 6C) and absence (Fig. 6B) of i- 
tRNA(AAC) expression, suggests this as the most likely explanation for methionine bearing Nluc peptides, not misacylation of $\mathrm{i}$-tRNA(AAC) with methionine.

(VaIRS) appears to interact with i-tRNA(AAC) as if it was a valine elongator tRNA and charge it with may be a significant contributor to the low initiation efficiency of i-tRNA(AAC). elongator tRNAs bear formylated N-terminal valine [8]. Using PRM mass spectrometry we readily

380 identified formylated valine peptides from Nluc expressed in the presence of $\mathrm{i}$-tRNA(AAC). $\mathrm{N}$ -

381 terminal de-formylation and methionine excision occur co-translationally in E. coli and we wanted to 
initiated proteins. Using structural modeling that compared the interaction of all possible formylated amino acids (except proline) to formylated methionine (Table 1), we found that the catalytic efficiency of hydrolysis of the formyl group attached to fVAS was likely lower in comparison to the native substrate fMAS (Figs. 8 and 9). The inability to remove the formyl group has been shown to compromise host viability $[46,47]$ and this would have potential implications if $i$-tRNA(AAC) was used more widely to control essential genes within the cell, or to express a protein that relies on quick removal of the $\mathrm{N}$-terminal residue for catalytic activity [48]. its interactions with $\mathrm{N}$-degron proteins such as by ClpS discriminator proteins that transfer the bound protein to ClpAP degradation complexes $[49,50]$. In theory, the inefficient removal of the formyl group from formylated-valine bearing proteins in our translation system should block recognition by ClpS and slow degradation, which was seen previously in formylated-phenylalanine initiated-proteins [8]. Surprisingly, we see the opposite effect, with i-tRNA(AAC) initiated proteins having significantly shorter in vivo lifetimes than methionine-bearing proteins (Fig. 7C). This feature may be useful when i-tRNA(AAC) is used as an orthogonal translation initiator if rapid protein turnover is a desirable feature, such as in biosensors [51], or whenever degradation tags might otherwise be deployed. Furthermore, the i-tRNA(AAC) initiated proteins may be used to quickly and

\section{Materials and Methods}

\section{Bacterial Strains}


410 growth, spectinomycin $(50 \mu \mathrm{g} / \mathrm{mL})$ for strains containing a pULTRA plasmid, and carbenicillin (100

$411 \mu \mathrm{g} / \mathrm{mL}$ ) for strains containing pET20b plasmids. All bacterial cultures within this study were

412 inoculated into $2 \mathrm{~mL}$ of media with appropriate antibiotics in $15 \mathrm{~mL}$ conical falcon tubes and grown

413 overnight (16 hours) in an Infors MT Multitron pro orbital shaker-incubator at 250 RPM rotating

414 orbitally at $25 \mathrm{~mm}$ diameter at $37^{\circ} \mathrm{C}$, unless stated otherwise. These stationary phase overnight

415 liquid cultures were back diluted to $0.1 \mathrm{OD}_{600}$ and grown in in $15 \mathrm{~mL}$ conical falcon tubes in an Infors

416 MT Multitron pro orbital shaker-incubator at 250 RPM rotating orbitally at $25 \mathrm{~mm}$ diameter at $37^{\circ} \mathrm{C}$,

417 unless stated otherwise. Bacterial growth parameters have been reported to the best of our

418 knowledge conforming with the MIEO v0.1.0 standard [53].

\section{Plasmid Construction}

To create the pULTRA::tac-metY(AAC) plasmid we designed a modified version of met $Y$ from

MG1655 (GenBank: U00096.3) where the anticodon region was changed from CAT to AAC (Table S4).

The pULTRA-CNF plasmid (Addgene\#48215) was linearized by PCR with oligos designed to flank the

metY gene (Table S5) and the modified metY(AAC) gene was then inserted using homologous

recombination (NEBuilder HiFi DNA Assembly kit (NEB\#E2621)). The pULTRA::tac-Empty control plasmid was constructed through the linearization of the pULTRA::tac-metY(AAC) plasmid via PCR backbone amplification with oligos (Table S4) and ligated. This control plasmid was designed to retain all of the elements of the pULTRA::tac-metY(AAC) plasmid, except for the metY gene. The pET20b::T7-(NNN)sfGFP reporter plasmids were from previous work Hecht, Glasgow [31]. The pET20b::T7-(GUU)Nluc6His was built using the pET20B plasmid and nluc gene (Table S4). Nluc was used instead of sfGFP for mass spectrometry due to its favorable tryptic cleavage pattern. 
Bacterial Fitness Analysis of fresh $\mathrm{LB}^{\mathrm{M}}$ and the appropriate antibiotics and grown at $37^{\circ} \mathrm{C}$ with shaking until cultures were at $0.6 \mathrm{OD}_{600}$. Following this, cells were back diluted to $0.1 \mathrm{OD}_{600}$ with a final volume of $200 \mu \mathrm{L}$ of $\mathrm{LB}^{\mathrm{M}}$ and appropriate antibiotics in a flat bottom 96 well plate (Sigma, cat\#P8116) and sealed with a gaspermeable transparent seal (Sigma cat\# Z380059). Within this plate, two different conditions were set up: an induced condition containing LB ${ }^{\mathrm{M}}$ with the appropriate antibiotics and $1 \mathrm{mM}$ IPTG and a control condition which only contained $\mathrm{LB}^{\mathrm{M}}$ and the appropriate antibiotics. Cells were grown for 7 hours at $37^{\circ} \mathrm{C}$ in a SPECTROStar Nano plate reader, with absorbance at $\mathrm{OD}_{600}$ readings occurring every 5 minutes. Growth rate $(\mu \mathrm{r})$ and maximum cell optical density $\left(\max \mathrm{DD}_{600}\right)$ were analyzed using the GrowthCurver R package [54].

\section{Fluorescence Measurements}

457 Following induction, $400 \mu \mathrm{L}$ of culture was transferred into a clear 96 -well plate (Sigma, 
phosphate-buffered saline (PBS) and transferred into a black clear bottom 96-well plates (Sigma,

\section{Flow Cytometry}

Bacterial cultures were prepared as for fluorescence measurements above. Following this, cells were diluted 100 -fold in PBS to reach the final cell concentration of approximately $10^{6} \mathrm{cfu} / \mathrm{mL}$ and measured on a CytoFLEX S (Beckman Coulter) using a FITC fluorescence channel with a $488 \mathrm{~nm}$ changes of 4-fold or more, with a statical significance of $p<0.01$.

\section{Expression and Purification of Nluc}

(GUU)N/uc6XHis plasmids were used to inoculate $5 \mathrm{~mL}$ of $\mathrm{LB}^{\mathrm{M}}$ supplemented with spectinomycin, 
The cell cultures were pelleted at 3,500 $\mathrm{xg}$ for $10 \mathrm{~min}$. The supernatant was discarded, and the cell pellets were chemically lysed using $0.4 \mathrm{~mL}$ lysis buffer (CelLytic B cell lysis reagent (Sigma-Aldrich \#B7310), $0.1 \mathrm{mg}$ lysozyme, 1x protease inhibitor (Roche \#04693132001), and 100 units of benzonase (Sigma-Aldrich \#E1014)). The resuspended cells were incubated at room temperature for 20 min to allow for sufficient lysis. The soluble protein fraction was then collected by centrifuging the cell lysate at $16,000 \mathrm{xg}$ for 10 minutes. The expressed C-terminal $6 x$ His-tagged Nluc was Ni-NTA purified using HisPurTMNi-NTA Resin (ThermoFisher scientific, \#88221) as per the HisPurTMNi-NTA Resin protocol. Equilibration, wash, and elution buffers were made using $300 \mathrm{mM}$ PBS with $20 \mathrm{mM}, 60$ $\mathrm{mM}$, and $500 \mathrm{mM}$ imidazole, respectively.

\section{Mass Spectrometry} cold acetone incubated overnight at $-20^{\circ} \mathrm{C}$ and pelleted via centrifugation at $16,000 \mathrm{xg}$ for $10 \mathrm{~min}$ at

$4^{\circ} \mathrm{C}$. The resulting protein pellet was resuspended in $8 \mathrm{M}$ Urea, $50 \mathrm{mM}$ Tris- $\mathrm{HCl}$ buffer ( $\mathrm{pH} \mathrm{8.0)}$ and diluted 5-fold by addition of $50 \mathrm{mM}$ Tris- $\mathrm{HCl}$ buffer ( $\mathrm{pH}$ 8.0). Protein samples were digested with 1:100 (w/w) trypsin/protein incubated at $37^{\circ} \mathrm{C}$ overnight, then digested again for 4 hours with fresh trypsin at $37^{\circ} \mathrm{C}$ (in the same amounts as previously). Peptides were then acidified with $1 \%(\mathrm{v} / \mathrm{v})$

506 formic acid, followed by a C18 stage tip clean up and filtration through glass fiber filter circles (Fisher 507 Scientific, \#09-804-24A). The peptides were then dried in a SpeedVac vacuum concentrator and resuspended to a final concentration of $1 \mu \mathrm{g} / \mu \mathrm{L}$ in $2 \%(\mathrm{v} / \mathrm{v})$ acetonitrile / $0.1 \%(\mathrm{v} / \mathrm{v})$ formic acid and 
513 Reconstituted peptides were injected onto a C18 reverse phase column and eluted over a 120-

514 minute linear gradient by increasing concentrations of elution buffer $(99.9 \%(\mathrm{v} / \mathrm{v})$ acetonitrile, $0.1 \%$

515 formic acid). An initial survey scan was conducted at 70,000 resolution with a scan range of 320 to

$5161,800 \mathrm{~m} / \mathrm{z}$, AGC target set to $3 \times 10^{6}$, and a maximum injection time of $100 \mathrm{~ms}$. An unscheduled

517 inclusion list for N-terminal peptides (File S1) was generated using Skyline [56](Version 20.1.0.155).

518 Predefined target precursors that were identified were subjected to high collision dissociation

519 fragmentation using a normalized collision energy of 27. Resulting product ions were analyzed in an $520 \mathrm{MS} / \mathrm{MS}$ scan set at 17,500 resolution, AGC target of $3 \times 10^{6}$, maximum injection time of $60 \mathrm{~ms}$, and a $5212.0 \mathrm{~m} / \mathrm{z}$ isolation window. Analysis of precursor and product ion spectra were analyzed using 522 MaxQuant (Version 1.6.17.0)[57] and Skyline (Version 20.1.0.155)[56].

\section{Protein Stability Assay}

BL21(DE3)pLysS strains harboring pULTRA and pET20b Nluc reporter plasmids were picked

526 from single colonies in biological triplicates and inoculated overnight with shaking in $5 \mathrm{~mL}$ of $\mathrm{LB}^{\mathrm{M}}$

527 supplemented with appropriate antibiotics. Overnight cultures were diluted 1:100 into $15 \mathrm{~mL}$ of

528 fresh $\mathrm{LB}^{\mathrm{M}}$ and grown at $37^{\circ} \mathrm{C}$ with shaking until all cultures reached mid-log phase $\left(0.6 \mathrm{OD}_{600}\right)$. The

529 cultures were then subsequently back diluted to $0.1 \mathrm{OD}_{600}$ into $15 \mathrm{~mL}$ fresh $\mathrm{LB}{ }^{\mathrm{M}}$ and in $50 \mathrm{~mL}$ Falcon

530 tubes. The cells were grown for 2 hours at $37^{\circ} \mathrm{C}$ with shaking prior to induction with $1 \mathrm{mM}$ IPTG.

531 After 1 hour of induction, the cells were pelleted by centrifugation at 2,500 $\mathrm{xg}$ for $10 \mathrm{~min}$. In order to

532 remove all of the IPTG in the media, the cells were washed with fresh LB $^{\mathrm{M}}$, and re-pelleted.

533 Following this, the cells were resuspended in $15 \mathrm{~mL}$ fresh $\mathrm{LB}^{\mathrm{M}}$, and the addition of $2 \%$ glucose, to

534 repress the production of both tRNA and Nluc. The cells were then grown for 12 hours at $37^{\circ} \mathrm{C}$ with

535 shaking. Luminescence was measured from $100 \mu \mathrm{L}$ of culture from each time point, that was mixed

536 with $100 \mu \mathrm{L}$ of pre-prepared Nano-Glo ${ }^{\circledR}$ Luciferase Assay Buffer + Substrate (Promega \# N1130) and

537 incubated for 20 minutes at room temperature. Following incubation, luminescence was measured 
bioRxiv preprint doi: https://doi.org/10.1101/2021.05.25.445580; this version posted May 25,2021 . The copyright holder for this preprint (which was not certified by peer review) is the author/funder, who has granted bioRxiv a license to display the preprint in perpetuity. It is made available under aCC-BY-ND 4.0 International license.

using a Synergy H1 Hybrid Multi-Mode Reader at 100 gain setting. Arbitrary luminescence units were then normalized by the absorbance $\left(\mathrm{OD}_{600}\right)$ measurement of the culture at the point of sampling.

\section{Protein:protein Interaction Stability and Docking Analyses}

Peptide binding stability and optimal docking of substrate tripeptides were calculated in Molsoft ICM version 3.9-2a [58] using the pdb-redo [59] refined structure of E. coli peptide deformylase $1 \mathrm{bs} 6$. The structure of peptide deformylase was cleaned of unnecessary small molecules and converted to an ICM object using an object conversion protocol that incorporates addition of hydrogens, optimisation of His, Asn and Gln rotamers, and assignment of protonation states and secondary structure [58].

The model of chains A (enzyme) and D (peptide MAS) was prepared by global optimisation of side chains and backbone annealing in ICM-Pro. Waters W1 and W2 (as defined by [36]) (waters 2041 and 2042, 1bs6), and $\mathrm{Ni}^{2+}$ were maintained in the active site for peptide binding stability calculations. Met1 was mutated to all side chains (except Pro) and relative protein:protein binding free energy $\Delta \Delta G$ calculated for all mutants [38]. Formylated peptides fMAS, fVAS and fAAS were built using the ICM-Pro ligand editor and energy minimised [60]. Formylated peptides were docked into the enzyme active site of $1 \mathrm{bs} 6$ chain $\mathrm{A}$ including $\mathrm{W} 1$ and $\mathrm{Ni}^{2+}$ using flexible ligand docking with relaxed covalent geometry, automatic assignment of charged groups, and fixed peptide-like amide bonds. The binding site was defined based on the position of the bound MAS peptide (1bs6, chain D) in the original structure (1bs6, chain A). Docking scores were calculated in ICM-Pro with docking effort of 5 and the top ten conformers stored for analysis of optimal binding poses [58]. 2D interaction diagrams were prepared in ICM-Pro and structural model figures were prepared with Chimera [61]. 
Acknowledgements

564

We recognize that this research was conducted on the traditional lands of the

565

Wattamattagal clan of the Darug nation. We thank Ariel Hecht for providing R code for the

566

production of several figures, Daniel McDougal for helpful discussions and feedback on the

567

manuscript, and the Australian Proteome Analysis Facility. AH was supported by a Macquarie

568

Research Excellence PhD Scholarship and CSIRO SynBio FSP Top-Up scholarship, DS supported by a

569

Macquarie Research Excellence PhD Scholarship, FW was supported by the Ramsay Fellowship of

570

Applied Science, and PRJ was supported by the Molecular Sciences Department, Faculty of Science \&

Engineering, and the Deputy Vice-Chancellor (Research) of Macquarie University.

572

573

Author Contributions

574

Andras Hutvagner: Conceptualization, Experimentation, Formal Analysis, Investigation,

575

Methodology, Visualization, Writing - Original Draft, Writing - Review, Funding acquisition.

576 Dominic Scopelliti: Conceptualization, Experimentation, Formal Analysis, Investigation,

577 Methodology, Visualization, Writing - Original Draft, Writing - Review.

578 Fiona Whelan: Conceptualization, Formal analysis, Investigation, Methodology, Visualization,

579 Writing - Original Draft, Writing - Review.

580 Paul R. Jaschke: Conceptualization, Writing - Review \& Editing, Supervision, Project administration,

$581 \quad$ Funding acquisition.

582

583 Conflicts of Interest

584 The authors declare no conflict of interest.

\section{Keywords}

mass spectrometry; molecular docking; formylation; synthetic biology; $\mathrm{N}$-end rule 
589 [1] Laursen BS, Sørensen HP, Mortensen KK, Sperling-Petersen HU. Initiation of protein 590 synthesis in bacteria. Microbiology and molecular biology reviews. 2005;69:101-23.

591 [2] Liu CC, Jewett MC, Chin JW, Voigt CA. Toward an orthogonal central dogma. Nature 592 chemical biology. 2018;14:103.

593 [3] Vincent RM, Wright BW, Jaschke PR. Measuring amber initiator tRNA orthogonality in a genomically recoded organism. ACS synthetic biology. 2019;8:675-85.

[4] Amiram M, Haimovich AD, Fan C, Wang Y-S, Aerni H-R, Ntai I, et al. Evolution of translation machinery in recoded bacteria enables multi-site incorporation of nonstandard amino acids. Nature biotechnology. 2015;33:1272-9.

[5] Ma NJ, Isaacs FJ. Genomic recoding broadly obstructs the propagation of horizontally transferred genetic elements. Cell systems. 2016;3:199-207.

600 [6] Link AJ, Mock ML, Tirrell DA. Non-canonical amino acids in protein engineering.

601 Current opinion in biotechnology. 2003;14:603-9.

602

603

604 [7] Hankore ED, Zhang L, Chen Y, Liu K, Niu W, Guo J. Genetic incorporation of noncanonical amino acids using two mutually orthogonal quadruplet codons. ACS synthetic biology. 2019;8:1168-74.

605 [8] Mayer C, Köhrer C, Kenny E, Prusko C, RajBhandary UL. Anticodon sequence mutants of Escherichia coli initiator tRNA: effects of overproduction of aminoacyl-tRNA synthetases, methionyl-tRNA formyltransferase, and initiation factor 2 on activity in initiation. Biochemistry. 2003;42:4787-99.

609 [9] Varshney U, RajBhandary UL. Initiation of protein synthesis from a termination codon.

610 Proceedings of the National Academy of Sciences. 1990;87:1586-90.

611 [10] Chattapadhyay R, Pelka H, Schulman LH. Initiation of in vivo protein synthesis with 612 non-methionine amino acids. Biochemistry. 1990;29:4263-8.

613 [11] Schulman LH, Pelka H. In vitro conversion of a methionine to a glutamine-acceptor 614 tRNA. Biochemistry. 1985;24:7309-14.

615 [12] Tharp JM, Ad O, Amikura K, Ward FR, Garcia EM, Cate JH, et al. Initiation of Protein 616 Synthesis with Non-Canonical Amino Acids In Vivo. Angewandte Chemie. 2020;132:314661750.

618 [13] Pallanck L, Schulman LH. Anticodon-dependent aminoacylation of a noncognate tRNA 619 with isoleucine, valine, and phenylalanine in vivo. Proceedings of the National Academy of 620 Sciences. 1991;88:3872-6.

621 [14] Tharp JM, Krahn N, Varshney U, Söll D. Hijacking translation initiation for synthetic 622 biology. ChemBioChem. 2020.

623 [15] Vincent RM, Yiasemides P, Jaschke PR. An orthogonal amber initiator tRNA functions similarly across diverse Escherichia coli laboratory strains. Matters. 2019;5:e201904000009. [16] Tharp JM, Vargas-Rodriguez O, Schepartz A, Söll D. Genetic Encoding of Three Distinct Noncanonical Amino Acids Using Reprogrammed Initiator and Nonsense Codons. ACS Chemical Biology. 2021;16:766-74.

630 [18] Antoun A, Pavlov MY, Lovmar M, Ehrenberg M. How initiation factors maximize the 631 accuracy of tRNA selection in initiation of bacterial protein synthesis. Molecular cell.

632 2006;23:183-93.

633 [19] Shine J, Dalgarno L. The 3'-terminal sequence of Escherichia coli 16S ribosomal RNA: 634 complementarity to nonsense triplets and ribosome binding sites. Proceedings of the National 635 Academy of Sciences. 1974;71:1342-6. 
[20] Kozak M. Regulation of translation via mRNA structure in prokaryotes and eukaryotes. Gene. 2005;361:13-37.

638 [21] Shetty S, Shah RA, Chembazhi UV, Sah S, Varshney U. Two highly conserved features of bacterial initiator tRNAs license them to pass through distinct checkpoints in translation initiation. Nucleic acids research. 2017;45:2040-50.

641 [22] Rodnina MV. Translation in prokaryotes. Cold Spring Harbor perspectives in biology. 2018;10:a032664.

643 [23] Giegé R, Puglisi JD, Florentz C. tRNA structure and aminoacylation efficiency. Progress in nucleic acid research and molecular biology. 1993;45:129-206.

645 [24] McClain WH. Rules that govern tRNA identity in protein synthesis. Journal of 646 molecular biology. 1993;234:257-80.

647 [25] Saks ME, Abelson J. The transfer RNA identity problem: a search for rules. Science. 648 1994;263:191-7.

649 [26] Sekine S-i, Nureki O, Sakamoto K, Niimi T, Tateno M, Gō M, et al. Major Identity 650 Determinants in the" Augmented D Helix" of tRNAGlufromEscherichia coli. Journal of 651 molecular biology. 1996;256:685-700.

652 [27] Schmitt E, Panvert M, Blanquet S, Mechulam Y. Crystal structure of methionyltRNAfMet transformylase complexed with the initiator formyl-methionyl-tRNAfMet. The EMBO Journal. 1998;17:6819-26.

655 [28] Guillon J-M, Meinnel T, Mechulam Y, Lazennec C, Blanquet S, Fayat G. Nucleotides of 656 tRNA governing the specificity of Escherichia coli methionyl-tRNAfMet formyltransferase. Journal of molecular biology. 1992;224:359-67.

658 [29] Simonetti A, Marzi S, Myasnikov AG, Fabbretti A, Yusupov M, Gualerzi CO, et al. Structure of the 30S translation initiation complex. Nature. 2008;455:416.

660 [30] Lancaster L, Noller HF. Involvement of 16S rRNA nucleotides G1338 and A1339 in discrimination of initiator tRNA. Molecular cell. 2005;20:623-32. [31] Hecht A, Glasgow J, Jaschke PR, Bawazer LA, Munson MS, Cochran JR, et al. Measurements of translation initiation from all 64 codons in E. coli. Nucleic acids research. 2017;45:3615-26.

665 [32] Firnberg E, Labonte JW, Gray JJ, Ostermeier M. A comprehensive, high-resolution map of a gene's fitness landscape. Molecular biology and evolution. 2014;31:1581-92. [33] Chan PP, Lowe TM. GtRNAdb: a database of transfer RNA genes detected in genomic sequence. Nucleic acids research. 2009;37:D93-D7.

669 [34] Love MI, Huber W, Anders S. Moderated estimation of fold change and dispersion for RNA-seq data with DESeq2. Genome biology. 2014;15:550. Crystallization of Functionally CompetentEscherichia coliPeptide Deformylase Forms Containing either Iron or Nickel in the Active Site. Biochemical and biophysical research communications. 1998;246:342-6. [36] Becker A, Schlichting I, Kabsch W, Groche D, Schultz S, Wagner AV. Iron center, substrate recognition and mechanism of peptide deformylase. Nature structural biology. 1998;5:1053-8. [37] Katritch V, Totrov M, Abagyan R. ICFF: A new method to incorporate implicit flexibility into an internal coordinate force field. Journal of computational chemistry. 2003;24:254-65.

[38] Schapira M, Totrov M, Abagyan R. Prediction of the binding energy for small molecules, peptides and proteins. Journal of Molecular Recognition. 1999;12:177-90. results and strategies for improvement. Journal of computer-aided molecular design. 2012;26:675-86. 
[40] Abagyan R, Totrov M. Biased probability Monte Carlo conformational searches and electrostatic calculations for peptides and proteins. Journal of molecular biology. 1994;235:983-1002. [41] Meinnel T, Blanquet S. Enzymatic properties of Escherichia coli peptide deformylase. Journal of bacteriology. 1995;177:1883-7.

691 [42] Wu X-H, Quan J-M, Wu Y-D. Theoretical study of the catalytic mechanism and metalion dependence of peptide deformylase. The Journal of Physical Chemistry B.

2007;111:6236-44.

694 [43] Horowitz J, Chu W-C, Derrick WB, Liu JC-H, Liu M, Yue D. Synthetase recognition determinants of E. coli valine transfer RNA. Biochemistry. 1999;38:7737-46. [44] Varshney U, RajBhandary UL. Role of methionine and formylation of initiator tRNA in initiation of protein synthesis in Escherichia coli. Journal of bacteriology. 1992;174:7819-26. [45] Giege R, Ebel J, Clark B. Formylation of mischarged E. coli tRNA Met f. FEBS letters. 1973;30:291-5.

[46] Guillon J-M, Mechulam Y, Schmitter J, Blanquet S, Fayat G. Disruption of the gene for Met-tRNA (fMet) formyltransferase severely impairs growth of Escherichia coli. Journal of bacteriology. 1992;174:4294-301. [47] Mazel D, Pochet S, Marliere P. Genetic characterization of polypeptide deformylase, a distinctive enzyme of eubacterial translation. The EMBO journal. 1994;13:914-23. [48] Liao YD, Jeng JC, Wang CF, Wang SC, Chang ST. Removal of N-terminal methionine from recombinant proteins by engineered E. coli methionine aminopeptidase. Protein Science. 2004;13:1802-10.

708 [49] Erbse A, Schmidt R, Bornemann T, Schneider-Mergener J, Mogk A, Zahn R, et al. ClpS is an essential component of the $\mathrm{N}$-end rule pathway in Escherichia coli. Nature. 2006;439:753.

[50] Schmidt R, Zahn R, Bukau B, Mogk A. ClpS is the recognition component for Escherichia coli substrates of the N-end rule degradation pathway. Molecular microbiology. 2009;72:506-17.

[51] Wan X, Ho TY, Wang B. Engineering prokaryote synthetic biology biosensors. Handbook of Cell Biosensors (ed Thouand, G). 2019:1-37. [52] Butzin NC, Mather WH. Crosstalk between diverse synthetic protein degradation tags in Escherichia coli. ACS synthetic biology. 2018;7:54-62.

[53] Hecht A, Filliben J, Munro SA, Salit M. A minimum information standard for reproducing bench-scale bacterial cell growth and productivity. Communications biology. 2018;1:1-9.

[54] Sprouffske K, Wagner A. Growthcurver: an R package for obtaining interpretable metrics from microbial growth curves. BMC bioinformatics. 2016;17:172.

[55] Peterson AC, Russell JD, Bailey DJ, Westphall MS, Coon JJ. Parallel reaction monitoring for high resolution and high mass accuracy quantitative, targeted proteomics. Molecular \& Cellular Proteomics. 2012;11:1475-88.

[56] MacLean B, Tomazela DM, Shulman N, Chambers M, Finney GL, Frewen B, et al. Skyline: an open source document editor for creating and analyzing targeted proteomics experiments. Bioinformatics. 2010;26:966-8.

[57] Cox J, Mann M. MaxQuant enables high peptide identification rates, individualized ppbrange mass accuracies and proteome-wide protein quantification. Nature biotechnology. 2008;26:1367-72.

[58] Abagyan R, Totrov M, Kuznetsov D. ICM-A new method for protein modeling and design: Applications to docking and structure prediction from the distorted native conformation. Journal of computational chemistry. 1994;15:488-506. 
bioRxiv preprint doi: https://doi.org/10.1101/2021.05.25.445580; this version posted May 25, 2021. The copyright holder for this preprint

(which was not certified by peer review) is the author/funder, who has granted bioRxiv a license to display the preprint in perpetuity. It is made available under aCC-BY-ND 4.0 International license.

735 [59] Joosten RP, Long F, Murshudov GN, Perrakis A. The PDB_REDO server for

736 macromolecular structure model optimization. IUCrJ. 2014;1:213-20.

737 [60] Totrov M, Abagyan R. Flexible protein-ligand docking by global energy optimization in

738 internal coordinates. Proteins: Structure, Function, and Bioinformatics. 1997;29:215-20.

739 [61] Pettersen EF, Goddard TD, Huang CC, Couch GS, Greenblatt DM, Meng EC, et al.

740 UCSF Chimera - a visualization system for exploratory research and analysis. Journal of

741 computational chemistry. 2004;25:1605-12. 